\title{
COMUNICAÇÃO E MOBILIZAÇÃO POLÍTICA NA INTERNET
}

\section{Communication and political mobilization on the internet Comunicación y movilización política en internet}

\author{
Kelly Prudencio ${ }^{1}$
}

\begin{abstract}
RESUMO
Os serviços de informação na internet criados pelos coletivos de movimentos sociais configuram uma prática do ativismo político contemporâneo. Apresentam-se como ferramentas de grande importância estratégica e de forma diferente do que tradicionalmente se chamou de mídia alternativa. A comunicação que se dá por esse ciberativismo se direciona a públicos específicos, utiliza linguagens híbridas e, apesar da clara oposição à grande mídia, se apropria dos seus códigos para subvertê-los em favor da constituição que aqui foi denominada mídia ativista. Essa experiência permite pensar como a internet participa no processo de mobilização política e também na democratização do debate público.
\end{abstract}

Palavras-chave: ativismo político; comunicação; mídia; internet.

\begin{abstract}
The websites created by social movements' collectives become a practice of contemporary political activism. They have a big strategic importance and present themselves in a different way, unlike the traditional alternative media. The communication that occurs by this cyber activism targets specific audiences, uses hybrid languages and, despite of its clear opposition to the mainstream media, appropriates its codes in order to subvert them in favor of what we call here activist media. This experience allows us to think about how the internet is present in the process of political mobilization and also in the public debate democratization.
\end{abstract}

Keywords: political activism; communication; media; internet.

\section{RESUMEN}

Los servicios de información en internet creados por los colectivos de movimientos sociales constituyen una práctica del activismo político contemporáneo. Se presentan como herramientas de gran importancia estratégica y de manera distinta de lo que tradicionalmente se llamó de media alternativa. La comunicación que se da por el ciberactivismo busca un target específico, utiliza lenguajes híbridos y, a pesar de la clara oposición a la gran media, se apropia de sus códigos para someterlos a favor de la constitución que aquí fue denominada media activista. Esa experiencia nos permite pensar como la internet participa en el proceso de movilización política y también en la democratización del debate publico.

Palabras clave: activismo político; comunicación; media; internet. ${ }_{1}$ Doutora em Sociologia Política. Professora do Programa de Pós-Graduação em Comunicação da Universidade Federal do Paraná.
Rua Bom Jesus, 650, Curitiba, Paraná, (41) 3313-2005, kellyprudencio@ufpr.br 
Aparentemente, o deslumbre inicial com a internet aos poucos é substituído por posturas mais realistas. Mitos foram construídos, derivados de antigas esperanças de democratização do acesso à informação. Os usos e os limites das ferramentas tecnológicas logo apontaram para a necessidade de observação mais criteriosa, o que resultou em alguns estudos importantes para a compreensão desse fenômeno contemporâneo.

Este artigo apresenta algumas considerações sobre a mobilização política pela/na internet, a partir de uma pesquisa realizada em websites com objetivos de ativismo político. $\mathrm{O}$ recorte foi feito pelos serviços de informação mantidos por coletivos de movimentos sociais ligados à rede mundial de contestação ao modelo de desenvolvimento socioeconômico, conhecidos como "movimentos antiglobalização" ou "movimentos por justiça global". Esses coletivos ficaram marcados pela sua ação via internet mobilização de quadros e contrainformação -, aliada a grandes manifestações "presenciais" contra o Banco Mundial, o Fundo Monetário Internacional e a Organização Mundial do Comércio.

Discutem-se aqui algumas mudanças no padrão organizacional da ação coletiva com a utilização da internet como ferramenta de mobilização e comunicação política e também a linguagem construída nos websites, nomeada aqui mídia ativista, o meio de comunicação dos movimentos sociais contemporâneos.

\section{Mitos que ainda rondam}

Como mostra Wolton (2003), o discurso da modernização passa hoje pelo entusiasmo com as novas tecnologias da informação $e$ comunicação (TICs), a ponto de assumir um caráter obrigatório e incontestável. O sucesso das "novas" tecnologias se deve, segundo o autor, ao fato de elas representarem uma "nova chance" para os que perderam as "antigas". O autor se refere à interessante oposição que se construiu entre as mídias de massa e as TICs, especialmente a internet. As primeiras estariam associadas a tudo o que é conservador $e$ as segundas, ao progresso.

A grande oferta de informação na internet poderia representar a realização do antigo ideal moderno da liberdade de imprensa, em que todos teriam acesso à informação e poderiam se habilitar para o debate público racional, em favor da constituição de uma opinião pública, agora com dimensões transnacionais. Mas o limite do desempenho técnico se evidencia no fato de que o acesso à informação não substitui a competência prévia para saber qual informação procurar e que uso fazer dela (WOLTON, 2003, p. 87).

Isso difere de muita coisa que já se falou sobre internet. Algumas análises supervalorizam o ambiente para a democratização da comunicação. Moraes (2002) entende que a possibilidade de transmitir as reivindicações se dá sem "os filtros ideológicos e as políticas editoriais da chamada grande mídia" e também permite "driblar o monopólio de divulgação, permitindo que forças contra-hegemônicas se expressem..."2.

Considerar que os filtros ideológicos, as formas de poder e de silenciamento das contradições não acontecem no ciberespaço é conceber que os atores sociais, pelo fato de se relacionarem com um ambiente tecnológico, despem-se de suas posições e não entram no ciberespaço também para competir definições - igualmente ideológicas - de realidade.

Posturas mais cautelosas apontam para o perigo do determinismo e, ao mesmo tempo em que reconhecem que as TICs facili-

\footnotetext{
${ }^{2}$ Na mesma direção, Lévy (1996, p. 203) afirma que "o ciberespaço é justamente uma alternativa para as mídias de massa clássicas. [...] encoraja uma troca recíproca e comunitária enquanto as mídias clássicas praticam uma comunicação unidirecional na qual os receptores estão isolados uns dos outros" (grifo meu).
} 
tam o armazenamento e circulação e agilizam as buscas, afirmam que elas não determinam o procedimento de interação comunicativa nem garantem a reflexão crítico-racional (MAIA, 2002). Portanto, se haverá ou não o debate, é algo que não pode ser decidido a priori, pois este é mais que uma pluralidade de vozes.

Dessa forma, se é possível entender a internet como um espaço em que todos podem falar, não é verdade que todos são ouvidos. Como frisa Maia (2002), as informações disponíveis na mídia devem ser consideradas, entre outras formas de conhecimento, como recursos preliminares a serem processados.

Ciberativismo - a mobilização na internet

Se a internet não está acessível a todos, pode-se pensar a comunicação dos movimentos sociais nela desenvolvida como ação de uma "minoria ativa" mais habilitada que uma idealizada "maioria crítica" (MELUCCI, 1996). Trata-se de uma visão mais realista, como quer Wolton (2003), sem impedir de verificar que processos de comunicação estão ocorrendo nesse (ciber)espaço.

Gustavo Lins Ribeiro (2002) coloca mais uma questão: como a internet altera as práticas políticas dos atores coletivos? Para o autor, o ciberespaço representa um novo domínio de contestação, sendo a internet a base tecnológica que abre a possibilidade do surgimento de uma "comunidade transnacional imaginada-virtual". Com isso, ele não quer dizer que a internet é a promessa de um "admirável mundo novo"; ao contrário, frisa que a inovação tecnológica é ambígua, apresentando tanto um potencial utópico quanto distópico. Ele quer, na verdade, pensar como o ativismo a distância muda a forma de fazer política na sociedade da informação.
$\mathrm{Na}$ internet, há superabundância de informação. A oferta supera a capacidade de processá-la, ocorrendo o que autores como Ramonet (1999) chamam de censura democrática ou white out: o excesso provoca desinformação. É diferente da censura autoritária, que restringe, proíbe e suprime informação, causando black out. Isso exige dos ativistas a definição clara de suas agendas.

E definir claramente as agendas depende do reconhecimento do adversário. Como na política contemporânea, esse adversário não se encontra em bunkers, ele é construído simbolicamente no que Ryan (1991) chama de frame contests, o que numa tradução ligeira significa "disputa de enquadramento". Daí que a expressão de Ribeiro "comunidade transnacional imaginada-virtual" sugere que a internet se constitui, para os ciberativistas, como uma comunidade que é imaginada, tanto quanto seus adversários (o que não significa que sejam irreais, mas construídos simbolicamente). Segundo ele, o testemunho a distância permite o ativismo (também a distância). Dessa forma, a internet amplia a esfera pública e a ação política, sem, contudo, substituir outras formas já institucionalizadas de relacionamento.

Portanto, não é a internet que cria um provável "movimento social transnacional", mas o suporte tecnológico agiliza os contatos e acelera a entrada de temas na agenda de discussão pública e o processo de tomada de decisões em relação a eles. Pois, na medida em que os atores em rede organizam a informação, atribuindo-lhe um significado diferente do estabelecido, eles mantêm a capacidade de produzir (ou anunciar) mudanças na sociedade.

Embora a internet abra a possibilidade para uma interatividade não observada nos outros veículos de comunicação e seja possível entendê-la como um espaço em que todos podem falar, não é verdade que todos são ouvidos (MAIA, 2002). Até porque o recurso da interatividade é pouco e raramente explorado pelos ativistas, como frisam van de Donk et al. (2004), 
que ainda notam que a comunicação na internet é ainda uma via de mão única.

Para os movimentos, a internet não é nem um meio externo - de broadcasting como a televisão, o rádio e os jornais - nem um meio interno - responsável somente pela produção de newsletters. Ela é ao mesmo tempo um meio interno e externo e não apenas uma ferramenta, mas também um alvo de protesto e dissenso. Por essa razão, seu uso pelos ativistas não faz dela apenas uma "mídia alternativa", em que é possível difundir suas visões, mas um espaço híbrido no qual atuam ativistas e jornalistas da mídia convencional.

Em virtude disso, embora os ativistas preguem o livre fluxo de informação, alguns meios de organizá-la e canalizá-la são necessários para evitar o white out, o que implica a necessidade de uma centralização, contrariando os desejos de uma comunicação sem nenhum controle. Conflitos sobre o que publicar ou não também existem, portanto, na cibercomunicação.

Como ferramenta de empoderamento dos movimentos sociais, sabe-se muito pouco sobre a internet. Alguns mitos, no entanto, Rucht (2004a) faz questão de combater. Em primeiro lugar, a mera existência de websites ativistas não significa que a mídia convencional foi ou será substituída pela internet como ação estratégica. A repercussão ainda é importante e esses websites estão restritos aos próprios ativistas $e$ simpatizantes.

As mobilizações transnacionais teriam sido impossíveis sem a rede, contudo, vários exemplos da era pré-internet mostram que sempre foi preciso longo período de preparação. Então é preciso diferenciar atividades impossíveis de se realizar sem a internet $e$ aquelas que foram por ela facilitadas.

$\mathrm{O}$ autor não acredita que a expansão da internet signifique que ela seja uma ferramenta de grande importância para a comunicação política nem que a presença na internet diminua a diferença de poder entre "fracos" e "fortes". Para ele, a tendência é o reforço dessa diferença, uma vez que ela também é fonte para os adversários dos ativistas, não sendo, portanto, uma prerrogativa dos movimentos por justiça global.

A justificativa de Rucht é que os ativistas já são usuários da internet e não há indícios da sua importância para a mobilização. A mídia convencional continua a ser a principal fonte de informação para não mobilizados. A internet é útil para quem já está habilitado a procurar informação nela. Por isso não está claro, para ele, se a internet é igualmente efetiva para a mobilização política como é para a reunião de informações. Também não há um controle de qualidade dessas informações. Se todos podem falar, fica difícil separar o joio do trigo, o que afeta a confiança nas informações veiculadas na rede.

Como a internet é um meio impessoal, os encontros ainda são importantes para reativar a confiança mútua. Por isso, os movimentos sociais continuam promovendo encontros para troca de informações e manifestações in loco, porque os protestos eletrônicos repercutem apenas na rede, mas não atingem diretamente a audiência nem os alvos institucionais.

\section{Mídia ativista}

Mas, então, como atuam os movimentos por justiça global hoje, cuja presença na internet tornou-se sua marca? Para Ford e $\mathrm{Gil}^{3}$, os ativistas de mídia tradicionalmente atuaram como repórteres ou documentaristas, mediando as notícias. Por meio das redes eletrônicas, eles passam a também se expressar diretamente, o que torna as fronteiras entre ativistas e profissionais de mídia cada vez mais indistintas.

$\mathrm{O}$ que se sabe é que a internet é um

${ }_{3}$ Capítulo intitulado "A internet radical", inserido em Downing (2002), p. 269-307. 
grande facilitador. É um engano considerá-la simplesmente como um dado, e que o único desafio é fazer uso efetivo dela. "A net não é a chave para uma estratégia 'alternativa' que permite aos movimentos sociais se tornar independentes da mídia convencional" (RUCHT, 2004b). Embora o autor não acredite que a internet afete as relações de poder existentes, o ciberativismo, mesmo circunscrito aos seus próprios quadros, vem se constituindo como força política importante, na medida em que os ativistas dos movimentos sociais se tornam fonte de informação para a mídia convencional.

Assim, a relação dos movimentos sociais com as TICs promove o surgimento de um tipo de comunicação mediada que aqui será chamado de mídia ativista. Algumas características dessa relação foram sistematizadas por van de Donk et al. (2004).

Em primeiro lugar, alguns movimentos são mais inclinados que outros a adotar as possibilidades das TICs em suas estratégias, com diferentes propostas e níveis de sofisticação. Os autores sugerem que a diversidade dos movimentos sociais se reflete no layout de seus websites na internet. Mas esta tem sido especialmente interessante para campanhas transnacionais que centralizam num foco o alvo dos protestos.

Em segundo lugar, a internet facilita formas tradicionais de protesto, como manifestações, mas dificilmente as substitui. Ela, contudo, certamente permite a mobilização imediata em todo o mundo. Isso leva ao seguinte aspecto, que é o fato de a internet afetar a estrutura interna das organizações de movimentos sociais, ajudando a intensificar a comunicação entre todas as partes de uma organização. Isso evidencia que as TICs ajudam a forjar alianças e coalizões (ainda que temporárias) entre diferentes movimentos.

Em consequência, serviços de informação especializados foram criados para dar suporte às redes, mas também para prover informação que tende a ser suprimida pelos meios de comunicação estabelecidos. Com isso, os grupos ativistas se tornam cada vez menos dependentes da cobertura jornalística.

A mídia ativista não apresenta homogeneidade. Há, inclusive, divergências entre os ativistas sobre o melhor uso da internet como espaço de comunicação para os movimentos sociais. Dessa forma, a análise mostra duas possiblidades para a cibercomunicação política: uma operada pelos ativistas de mídia e outra pelos que chamei de jornativistas. A distinção não é rígida, servindo apenas como categorização analítica, mesmo porque os websites analisados compartilham o material informativo produzido.

A diferença está na concepção do trabalho de contrainformação. Assim, a mídia ativista varia conforme as características dos atores que produzem a informação, bem como conforme as relações entre os grupos ativistas e seus adversários. Os ativistas de mídia utilizam uma linguagem mais combativa e claramente contrária ao enfoque comumente difundido sobre os temas, enquanto os jornativistas apostam na linguagem referencial do jornalismo para obter mais credibilidade e interferir pragmaticamente nos rumos das decisões políticas. Para os ativistas de mídia, o conteúdo prevalece sobre a forma e, para os jornativistas, é a forma que antecede o conteúdo.

Assim, ativistas provenientes de organizações um pouco mais enfáticas na sua crítica ao neoliberalismo e, por extensão, à mídia e à imprensa corporativas, organizam a produção da informação para o fortalecimento dos seus pontos de vista e utilizam uma linguagem claramente militante, a qual predomina sobre o código legitimado do jornalismo. São os ativistas de mídia, aqueles que empreendem projetos de contrainformação como extensão da sua ação política ${ }^{4}$.

\footnotetext{
${ }_{4}^{4}$ Representados na pesquisa pelos coletivos Rebelion (www.rebelion.org), La Haine (www.lahaine.org) e Nodo50 (www.nodo50.org).
} 
Ainda que os ativistas vejam seu trabalho como um "projeto de contrainformação", com o objetivo de "combater o ruído com aparência de música que emana dos gigantes midiáticos", o que eles conseguem com a reunião de textos das mais variadas origens é gerar mais ruído e restringir seu uso aos seus próprios produtores.

Com isso, o que orienta a ação dos ativistas de mídia é a imagem de um público. Falar para um público significa construir uma comunidade imaginada em torno de questões que são compartilhadas, ainda que não haja consenso absoluto. É justamente a divergência que forma um público em torno de uma questão (BLUMER, 1946). Se há muitas questões, é difícil identificar seus públicos e, consequentemente, desenhar um quadro de ação.

$\mathrm{Na}$ forma de autodenominação - e também demarcação do lugar do discurso -, os ativistas de mídia apresentam seu público: antiglobalistas, anticapitalistas, socialistas, rebeldes... Embora concretamente esses públicos sejam os próprios ativistas (ou a rede de movimentos sociais à qual estão conectados), a construção do público é necessária para configurar a rede.

Quanto mais seletivo em relação à informação é o coletivo, mais padronizada é a forma de expressão. Instala-se o dilema: quanto mais próximos ao padrão jornalístico de organização da informação, mais fácil se torna a leitura e, consequentemente, mais penetração no público. As armas do inimigo são as mais eficazes para combatê-lo.

Interessante notar, por fim, que há pouca utilização dos recursos multimídia disponíveis na internet. Raramente se encontram fotos nos websites, as quais poderiam dar equilibrio ao peso dos textos. Também os recursos de interatividade não são explorados, o que, junto com a necessidade de selecionar o material que vai para a página, acaba por frustrar um dos principais pressupostos de uma mídia "alternativa": a participação dos usuários na produção de informação.

Organizações consideradas mais institucionalizadas concebem seus serviços de informação como projetos independentes $e$ com metas pragmáticas. Ainda que questionem os procedimentos da imprensa, utilizam-nos para noticiar os acontecimentos que julgam negligenciados. Dessa forma, constroem seus próprios critérios de noticiabilidade, os quais vão orientar a seleção das informações que podem virar notícia. Essas equipes são formadas pelos jornativistas, que fazem dos serviços de informação não apenas uma extensão do seu ativismo, mas a sua estratégia principal.

O jornativismo é um espaço de atuação intermediário entre a perícia e o engajamento. Os jornativistas atuam ao mesmo tempo como profissionais da informação sem, contudo, aderir ao princípio da imparcialidade, assumindo claramente seu posicionamento. Este pode, então, ser pensado como um campo específico e privilegiado da ação política dos atores coletivos contemporâneos.

Observa-se nesses serviços ${ }^{5}$ uma crítica à grande imprensa que, contudo, não recusa todos os seus pressupostos. Como qualquer projeto político, não está livre de contradições entre a proposta e a execução. $\mathrm{O}$ aspecto inova-

\footnotetext{
${ }^{5}$ Os coletivos englobados na noção de jornativismo são: a Associação pela Tributação das Transações Financeiras em Apoio aos Cidadãos (Attac), criada em 1998, por ocasião de uma reunião em Paris depois do apelo de um editorial do jornal Le Monde Diplomatique, escrito pelo seu diretor Ignácio Ramonet, no qual examinava a possibilidade de controle internacional dos mercados financeiros e suas instituições. A inspiração veio do prêmio Nobel de Economia, o americano James Tobin, cuja proposta de taxar em $0,1 \%$ as transações financeiras foi adotada como principal campanha - a conhecida Taxa Tobin. Seu surgimento coincide com as primeiras manifestações por justiça global. A Attac é até hoje uma das principais organizadoras do Fórum Social Mundial. Outro é o Independent Media Center ou Indymedia, que foi criado em 1999 para a cobertura das manifestações contra a Organização Mundial do Comércio, em Seattle, nos Estados Unidos. Neste momento, a rede de movimentos por justiça global ganhou as páginas da imprensa, sendo por esta nomeada de "movimentos antiglobalização". É pelo Indymedia que "justiça global" passa a designar a convergência dessa rede.
} 
dor desses serviços é justamente a recriação do conceito de "alternativo": não se trata de voltar as costas para a mídia de massa, mas construir outros pontos de vista a partir de seu próprio código reconhecido. Com isso, eles, ao mesmo tempo em que o contestam, atuam sobre ele.

A internet é, no caso específico da Attac, o principal instrumento do que eles chamam de "renovação dos repertórios de ação" (LE GRIGNOU; PATOU, 2004). Seu uso é encorajado para organização dos movimentos sociais e para apoiar sua causa. A forma virtual do movimento, neste caso, precede sua forma física. Mas também há o problema da superlotação de textos; segundo os autores, cerca de 20 novos textos são colocados no website a cada dia. Uma maneira de cortar é a especialização de competências.

The internet could then be considered as an efficient tool keeping with the process of "frame extension" (Snow et al., 1986, p. 472). It can also be linked to the process of "frame clouding", i.e. the loss of any thematic visibility of the movement, which would then look like a hotchpotch of ideas, as a local member once said. So, on the one hand, the internet makes visible the fragmented plurality of its action by listing together subjects and causes. On the other hand, it simultaneously makes homogeneous and coherent a set of analyses, activities and movements, which would otherwise be scattered. For ATTAC's supporters, "everything is connected when it comes to world globalization" (LE GRIGNOU; PATOU, 2004, p. 172).

A relação entre o conselho científico, que decide a política de comunicação, e os ativistas é de cima pra baixo, mas não parece aborrecer ou incomodar os ativistas, que aceitam a assimetria de conhecimento. A internet é, então, o vetor dessa empreitada político-pedagógica.

\section{O consumidor político}

Ao privilegiar as campanhas internacionais, os ativistas acabam por criar um público que Rosenkrands (2004) chama de "consumidor político": o público dos websites anticorporações. O consumidor político pode ser definido como uma pessoa que leva seriamente em consideração valores quando deliberadamente compra ou deixa de comprar certos produtos para atingir uma meta política.

Uma das características dessas campanhas é que elas se voltam contra uma corporação, numa estratégia de educação pública, para "dar um exemplo", influenciar agenda pública e acordar políticos (ROSENKRANDS, 2004, p. 60). A lógica é: se as companhias se apresentam como mais que provedoras de produtos, como ligadas a um estilo de vida e com responsabilidade social, então devem estar abertas ao escrutínio político.

O crescimento da importância da imagem das corporações tornou-as mais vulneráveis. Essa vulnerabilidade é explorada pelos ativistas, o que Naomi Klein ${ }^{6}$ chama de brand boomerang. Como essas marcas são conhecidas, elas atingem um público maior de forma mais contundente. Em vez de discutir globalização, os ativistas discutem a ação de uma corporação. Segundo Klein, as empresas não são o alvo principal, mas uma "porta".

Os websites são usados basicamente para distribuir informação. Facilitam o fluxo de informação, internamente entre os movimentos e externamente em relação à imprensa e demais cidadãos. "Websites literally bring activism to a computer near you" (ROSENKRANDS, 2004, p. 76).

Essas campanhas evidenciam o objetivo comum dos ativistas: tornar transparentes os processos de decisão política (accountability). Dessa forma, a atuação desses projetos nos

\footnotetext{
${ }^{6}$ Entrevista realizada por Rosenkrands, 2004.
} 
websites aponta para mudanças na forma de fazer política, baseadas na luta pelo poder da nomeação dos problemas. E, nisso, o jornativismo emerge como estratégia fundamental.

A mídia ativista é, então, a forma de expressão da rede dos movimentos sociais contemporâneos. Cada nó da rede tem suas conexões, as quais influenciam na maneira de enquadrar as informações. Ela não atinge a pureza das suas intenções: a indistinção entre produtores e consumidores da informação, ausência de censura, pluralismo de opiniões. A razão disso é que a organização da informação exige o ajuste à visão de mundo que une os ativistas em torno de um objetivo. Exige ainda a utilização de uma linguagem reconhecida socialmente - o jornalismo -, importando dela sua forma tipificada de construção da realidade. Do contrário, a ação perde força e frustra a comunicação de suas demandas.

\section{REFERÊNCIAS}

BAUMAN, Zygmunt. Comunidade. Rio de Janeiro: Jorge Zahar, 2003.

\section{1.}

. Modernidade líquida. Rio de Janeiro: Jorge Zahar,

BLUMER, Herbert. Massa, público e opinião pública (1946). In: COHN, Gabriel. Comunicação e indústria cultural. São Paulo: T. A. Queiroz, 1987.

CASTELLS, Manuel. A sociedade em rede. A era da informação: economia, sociedade e cultura. Rio de Janeiro: Paz e Terra, 1999.

DOWNING, John. Mídia radical. Rebeldia nas comunicações e movimentos sociais. São Paulo: Senac, 2002.

LE GRIGNOU, Brigitte; PATOU, Charles. ATTAC(k)ing expertise: does the internet really democratize knowledge? In: VAN DE DONK, Wim; LOADER, Brian D.; NIXON, Paul G.; RUCHT, Dieter. Cyberprotest. New media, citizens and social movements. London: Routledge, 2004.

LÉVY, Pierre. O que é virtual? São Paulo: 34, 1996.

MAIA, Rousiley. Redes cívicas e Internet. Do ambiente informativo denso às condições da deliberação pública. In: EINSENBERG, José (Org.). Internet e política. Teoria e prática da democracia eletrônica. Belo Horizonte: UFMG, 2002.
Essa necessidade também impossibilita construir um quadro homogêneo para as informações. Por isso, os ativistas de mídia atuam de forma diferente dos jornativistas. No entanto, suas informações são compartilhadas e, se não há unidade de projetos, pelo menos há a partilha de um quadro de referência, sobre o qual produzem novos ajustes de sentido.

Essa mídia é online e se vale dos recursos que tal meio dispõe e, no contexto do ativismo político, evidencia aquelas conexões nos hyperlinks que constrói. Seu público é formado pelos próprios ativistas, mas alcança outras redes e cria a figura do consumidor político. Dessa forma, povoa o ciberespaço com produtos informativos diferentes, cujas características são aqui englobadas na noção de mídia ativista.

MELUCCI, Alberto. A invenção do presente. Petrópolis: Vozes, 2001.

. Acción colectiva, vida cotidiana y democracia. El Colégio de México, 1999.

. Challenging codes. Colletive action in the information age. Cambridge: University Press, 1996.

MORAES, Denis de. O ativismo digital (2001). Disponível em: <http://www.bocc.ubi.pt>.

. Comunicação virtual e cidadania (2002). Disponível em: < http://www.saladeprensa.org/art156.htm>.

RIBEIRO, Gustavo Lins. Política cibercultural. Ativismo político à distância na comunidade imaginada-virtual. In: ALVAREZ, S; DAGNINO, E; ESCOBAR, A. Cultura e política nos movimentos sociais latino-americanos. Belo Horizonte: UFMG, 2000.

ROSENKRANDS, Jacob. Politicizing Homo economicus: analysis of anti-corporate websites. In: VAN DE DONK, Wim; LOADER, Brian D.; NIXON, Paul G.; RUCHT, Dieter. Cyberprotest. New media, citizens and social movements. London: Routledge, 2004.

RUCHT, Dieter. The quadruple 'A': media strategies of protest movements since the 1960s. In: VAN DE DONK, Wim; LOADER, Brian D.; NIXON, Paul G.; RUCHT, Dieter. 
Cyberprotest. New media, citizens and social movements. London: Routledge, 2004a.

The internet as a new opportunity for transnational protest groups. Mimeo. Wissenschaftzentrum Berlin für Sozialforschung. Arbeitsgruppe Politische Öffentlichkeit und Mobilisierung, 2004b.

RYAN, Charlotte. Prime time activism. Media strategies for grassroots organizing. Boston: South End Press, 1991.
VAN AELST, Peter; WALGRAVE, Stefaan. New media, new movements? The role of internet in shaping the 'antiglobalization' movement. In: VAN DE DONK, Wim; LOADER, Brian D.; NIXON, Paul G.; RUCHT, Dieter. Cyberprotest. New media, citizens and social movements. London: Routledge, 2004.

WOLTON, Dominique. Internet, e depois? Uma teoria crítica das novas mídias. Porto Alegre: Sulina, 2003.

Texto recebido em 20 de agosto de 2009. Texto aprovado em 2 de março de 2010. 